
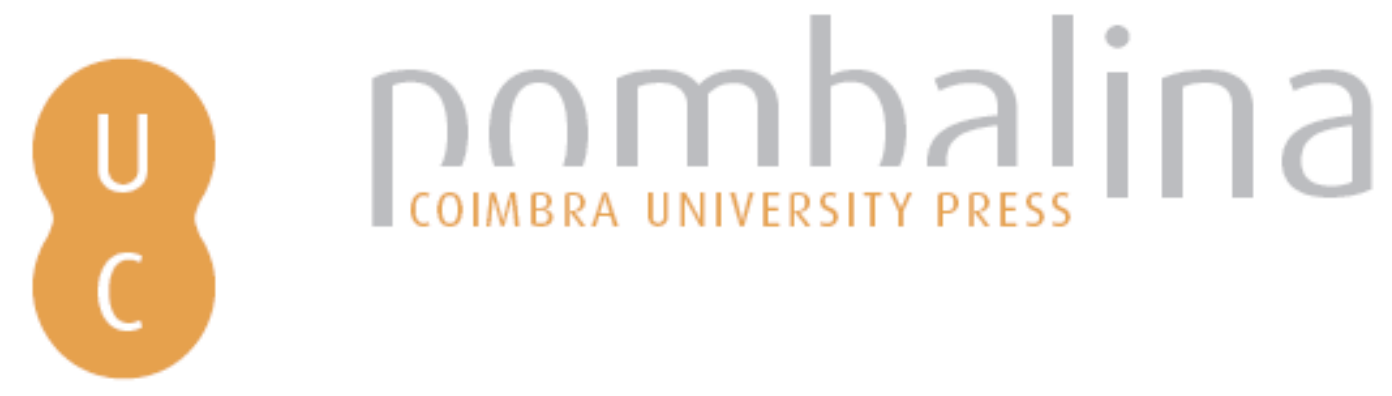

\title{
Geotecnologias aplicadas ao monitoramento de incêndios florestais na região da REDEC-I 7 do estado de São Paulo - Brasil
}

\author{
Autor(es): $\quad$ Cavarsan, Evandro Antônio; Lopes, Eymar Silva Sampaio; Magnoni \\ Júnior, Lourenço \\ Publicado por: Imprensa da Universidade de Coimbra; RISCOS - Associação \\ Portuguesa de Riscos, Prevenção e Segurança
}

URL

persistente:

URI:http://hdl.handle.net/10316.2/34963

DOI:

DOI:http://dx.doi.org/10.14195/978-989-96253-3-4_22

Accessed : $\quad$ 26-Apr-2023 03:46:04

A navegação consulta e descarregamento dos títulos inseridos nas Bibliotecas Digitais UC Digitalis, UC Pombalina e UC Impactum, pressupõem a aceitação plena e sem reservas dos Termos e Condições de Uso destas Bibliotecas Digitais, disponíveis em https://digitalis.uc.pt/pt-pt/termos.

Conforme exposto nos referidos Termos e Condições de Uso, o descarregamento de títulos de acesso restrito requer uma licença válida de autorização devendo o utilizador aceder ao(s) documento(s) a partir de um endereço de IP da instituição detentora da supramencionada licença.

Ao utilizador é apenas permitido o descarregamento para uso pessoal, pelo que o emprego do(s) título(s) descarregado(s) para outro fim, designadamente comercial, carece de autorização do respetivo autor ou editor da obra.

Na medida em que todas as obras da UC Digitalis se encontram protegidas pelo Código do Direito de Autor e Direitos Conexos e demais legislação aplicável, toda a cópia, parcial ou total, deste documento, nos casos em que é legalmente admitida, deverá conter ou fazer-se acompanhar por este aviso.

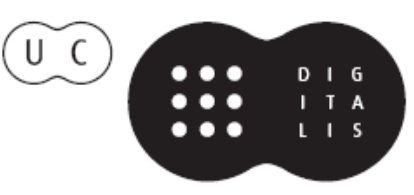



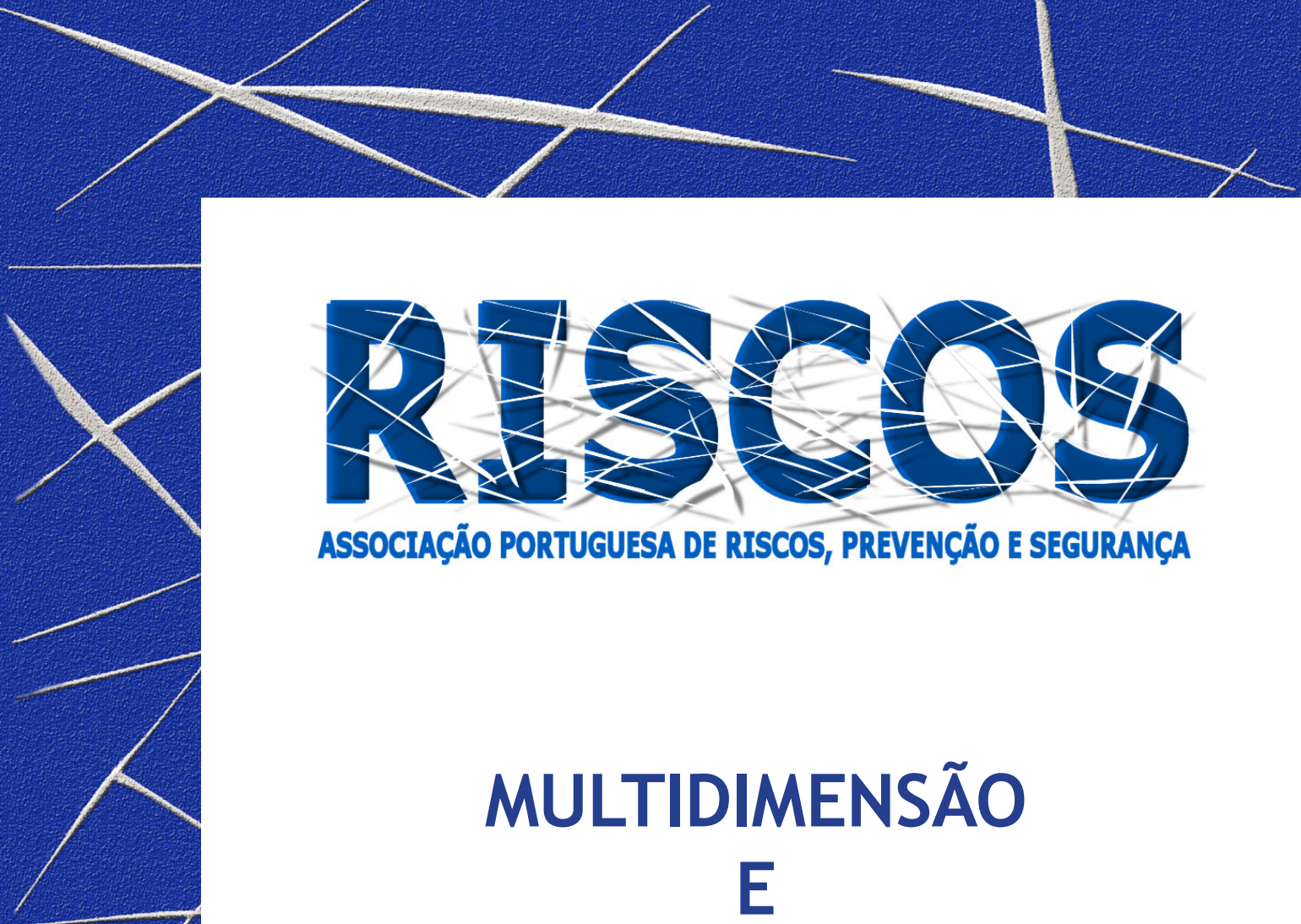

ASSOCIAÇÃO PORTUGUESA DE RISCOS, PREVENCCÃO E SEGURANÇA

MULTIDIMENSÃO

E
TERRITÓRIOS DE RISCO

III Congresso Internacional

I Simpósio Ibero-Americano

VIII Encontro Nacional de Riscos

Guimarães

2014 


\title{
GEOTECNOLOGIAS APLICADAS AO MONITORAMENTO DE INCÊNDIOS FLORESTAIS NA REGIÃO DA REDEC-I 7 DO ESTADO DE SÃO PAULO - BRASIL
}

\author{
Evandro Antônio Cavarsan \\ Coordenadoria de Defesa Civil de Cabrália Paulista \\ defesacivil@cabralia.sp.gov.br \\ Eymar Silva Sampaio Lopes \\ Instituto Nacional de Pesquisas Espaciais \\ eymar@dpi.inpe.br \\ Lourenço Magnoni Júnior \\ Centro Estadual de Educação Tecnológica Paula Souza \\ lourenco.junior@fatec.sp.gov.br
}

\begin{abstract}
RESUMO
A utilização de sistemas computacionais aplicados a questões do meio ambiente pode ser complexa e requer muitas variáveis a serem modeladas. Na literatura existem diversos modelos ambientais para as mais diversas aplicações como incêndios, enchentes, deslizamentos, entre outras. 0 desenvolvimento de geotecnologias com monitoramento em tempo-real de dados ambientais permite acompanhar as mudanças climáticas com potencial de deflagrar desastres. Neste contexto o Centro Integrado de Alerta de Desastres Naturais (CIADEN) instalado na Escola Técnica Astor de Mattos Carvalho de Cabrália Paulista - SP vem desenvolvendo aplicações fazendo uso da plataforma TerraMA² do Instituto Nacional de Pesquisas Espaciais (INPE). 0 objetivo deste trabalho é apresentar o monitoramento efetuado através de análises e alertas a incêndios florestais realizado na região de atuação da Regional da Defesa Civil do Estado de São Paulo Região Administrativa de Bauru (REDEC-I 7) através do CIADEN, onde concentram-se importantes empresas na área de reflorestamento e silvicultura como a DURATEX, SUZANO e LWARCEL. O sistema de monitoramento desenvolvido utiliza dados hidrometeorológicos coletados pelo INPE através dos sensores dos satélites GOES, NOAA e METEOSAT, variáveis como umidade relativa do ar, precipitação acumulada, temperatura, velocidade e direção do vento e focos de queimadas, que permitem definir índices de perigo a incêndios florestais. A área monitorada compreende os talhões de Eucalipto e Pinus sp. que estão localizados dentro dos 39 municípios que integram a REDEC-I 7. As análises de risco de incêndios são realizadas sobre as condições hidrometeorológicas dentro e num raio no entorno dos talhões. Sobre condições de baixa umidade, número de dias sem chuva, intensidade de vento, altura do dossel, presença de focos de queimadas nas faixas de distância de 5 à $10 \mathrm{~km}$ são os principais parâmetros para produzir alertas em quatro níveis, isto é, observação, atenção, alerta e alerta máximo. 0 sistema encontra-se em fase de implantação, mas os primeiros resultados já demonstram promissores para os agentes de combate a incêndios florestais na região.
\end{abstract}

Palavras-chave: Geotecnologias, Monitoramento, Incêndios Florestais, CIADEN, TerraMA²

\section{Introdução}

Incêndio florestais estão entre os desastres naturais que estão relacionados com a intensa redução das precipitações hídricas (CASTRO, 2003), sendo um grave problema ambiental que afeta não só o território brasileiro, mas também outros países como Estados Unidos, Canadá, Austrália, países da União Européia e países do Sudeste Asiático. Apesar de serem desastres dito naturais, aqui no Brasil, a quase totalidade dos incêndios são resultantes das queimadas causadas por atividades antrópicas, devido o uso inadequado de recursos naturais, como por exemplo, o desmatamento desordenado e as queimadas para a limpeza de pasto e preparo do plantio (SOUZA et al ., 2004), ou anda por incêndios criminósos.

Apesar do aperfeiçoamento das técnicas de controle e combate de incêndios florestais disponíveis, ainda há falta de um programa institucional consistente que contribua para redução 
deste cenário. Neste caso, a melhoria das técnicas de prevenção e combate não pode ser feita somente pela adoção de tecnologias disponíveis em outros países, mas sim através de programas que visem aprimorar e aproveitar as experiências, desenvolver novas geotecnologias, fazendose a devida adequação à realidade brasileira.

Outro fato agravante deve-se a falta de informações integradas em âmbito nacional ou mesmo regional, que resulta em sérios problemas para os técnicos que atuam na prevenção e combate aos incêndios florestais, razão pela qual este trabalho apresenta o trabalho que vem sendo desenvolvido pelo Centro Integrado de Alerta de Desastres Naturais (CIADEN).

Dentre as medidas preventivas a utilização de um índice de perigo a incêndio confiável é fator fundamental para um planejamento mais eficiente das medidas de prevenção e para a adoção de ações rápidas e efetivas nas atividades de combate aos incêndios florestais, visando a redução das perdas e, consequentemente, dos prejuízos financeiros advindos da sua ocorrência.

O objetivo principal deste trabalho é apresentar o monitoramento efetuado através de análises e alertas a incêndios florestais realizado na região de atuação da Regional da Defesa Civil do Estado de São Paulo Região Administrativa de Bauru (REDEC-I 7) fazendo uso da plataforma TerraMA² (LOPES, 2012) do Instituto Nacional de Pesquisas Espaciais - INPE. A Figura 1 mostra a localização da área de estudo.

Como objetivos secudários desse trabalho podemos citar:

- Implementar do Índice de Perigo de Angstron e Monte Alegre modificados;

- Implentar o Risco eminente baseado no índice de perigo e ocorrencias de focos de queimada próximos;

- Disponibilizar análises com o TerraMA2 no aplicativo web desenvolvido pelo CIADEN.

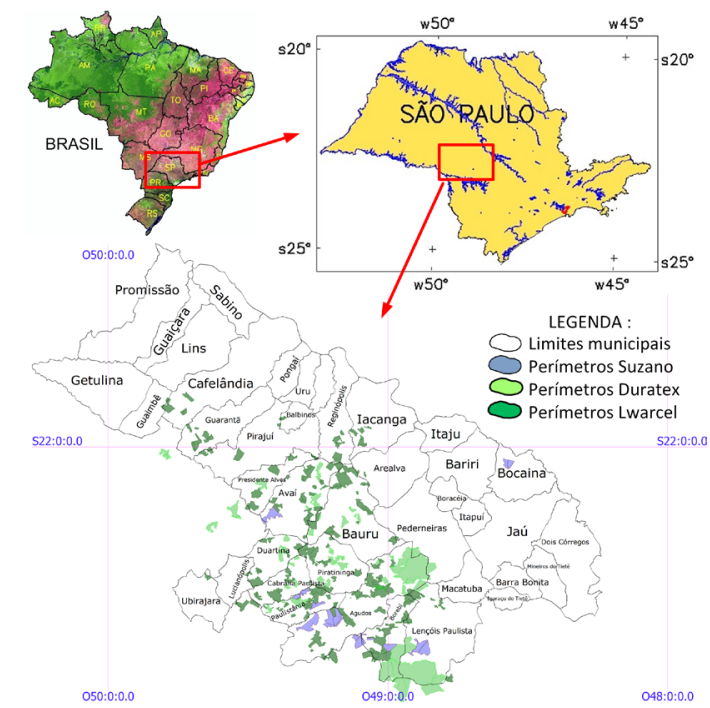

Figura 1 - Localização da área de estudo e perímetros das empresas de refloretamento.

\section{Materiais e Métodos}

Para desenvolvimento das análise foram utilizados dados hidrometorológicos disponíveis na Divisão de Satélites Ambientais (DSA) e do Centro de Previsão de Tempo e Estudos Climáticos (CPTEC), ambos do INPE. Os seguintes dados foram utilizados: 
- Precipitação estimada por satélite GOES - produto Hidroestimador;

- Precipitação acumulada em 24 horas por satélite GOES;

- Número de dias sem chuva - produto intergrado por satélite TRMM e estações pluviométricas;

- Umidade média nos últimos 5 dias - média da umidade relativa mínima do ar;

- Previsão numérica de tempo da precipitação em 60 minutos por modelo Eta;

- Previsão numérica de tempo da umidade relativa em 6 horas por modelo Brams;

- Previsão numérica de tempo da temperatura em 6 horas por modelo Brams;

- Focos de queimadas por satélite Meteosat.

Para realizar análises com os dados acima, os seguintes mapas estáticos foram incorporados ao banco de dados:

- Mapa municipal do Estado de São Paulo e REDEC-17;

- Perímetros das empresas Suzano, Duratex e Lwarcel de refloretamento.

Dois índices de perigo de incêndio foram utilizados e modificados para se ajustar aos dados ambientais disponíveis. No índice de Angstrom foram utilizados dados de previsão numérica de 6 em 6 horas até o limite de 24 horas para temperatura e umidade. Nota-se que para calcular este índice foi utilizado o maior valor de temperatura prevista e o menor de umidade relativa para um período de 24 horas a partir do horário atual.

Para o cálculo do índice de Monte Alegre foram utilizados dados de número de dias sem chuva e umidade relativa do ar nos últimos 5 dias. Além disso foi utilizado a previsão numérica para as próximas 6 horas, que permitiu definir porcentagens de redução do valor desse índice frente a probabilidade de chuva.

Uma outra análise realizada a partir desses índices foi realizada de forma integrada com a ocorrência de focos de queimadas do INPE, a qual permite alertar áreas que em se encontrando em estado de alerta, podem passar para alerta máximo caso exista focos próximos aos perímetros pré determinados das propriedades que estão sob monitoramento do CIADEN.

O Quadro I mostra os programas escritos em LUA para cálculo dos dois índices de perido a incêndio.

\section{Quadro I - Programas em LUA para cálculos dos índices de perigo a incêndio.}

\begin{tabular}{|c|c|}
\hline $\begin{array}{l}\text {-- Inicio - Índice de Angstrom } \\
\text { local T1 = soma_pn('Temp2m_brams5km', 1, 1) } \\
\text { local T6 = soma_pn('Temp2m_brams5km', 6, 6) } \\
\text { local T12 = soma_pn('Temp2m_brams5km', 12, 12) } \\
\text { local T18 = soma_pn('Temp2m_brams5km', 18, 18) } \\
\text { local T24 = soma_pn('Temp2m_brams5km', 24, 24) } \\
\text { local TMax = math.max(T1,T6,T12,T18,T24) } \\
\text { local H1 = soma_pn('Ur2m_brams5km', 1, 1) } \\
\text { local H6 = soma_pn('Ur2m_brams5km', 6, 6) } \\
\text { local H12 = soma_pn('Ur2m_brams5km', 12,12) } \\
\text { local H18 = soma_pn('Ur2m_brams5km', 18, 18) } \\
\text { local H24 = soma_pn('Ur2m_brams5km', 24, 24) } \\
\text { local HMin }=\text { math.min(H1,H6,H12,H18,H24) } \\
\text { local B }=0.05 \text { * HMin - 0.1* (TMax - 27) } \\
\text { add_value(B, 'Indice de Angstron') } \\
\text { if B > } 3 \text { then } \\
\text { return } 0 \text {-- Normal } \\
\text { elseif B > } 2.5 \text { then } \\
\text { return } 1 \text {-- Observacao } \\
\text { elseif B > } 1.5 \text { then } \\
\text { return } 2 \text {-- Atencao } \\
\text { elseif B > } 1 \text { then } \\
\text { return } 3 \text {-- Alerta } \\
\text { else } \\
\text { return } 4 \text {-- Alerta maximo } \\
\text { end }\end{array}$ & 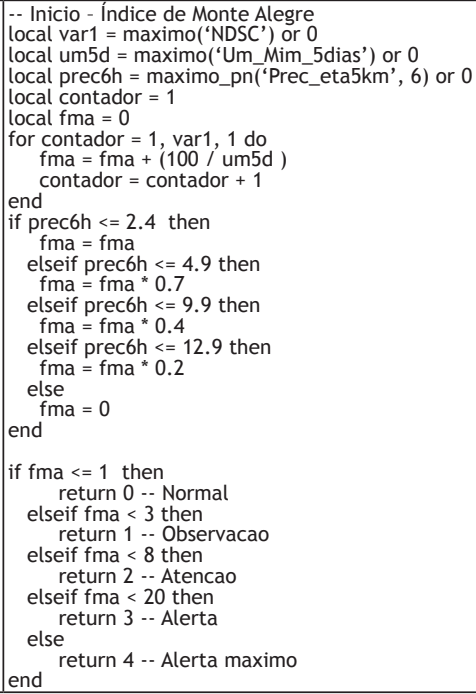 \\
\hline
\end{tabular}




\section{Resultados}

Os resultados do Cálculo
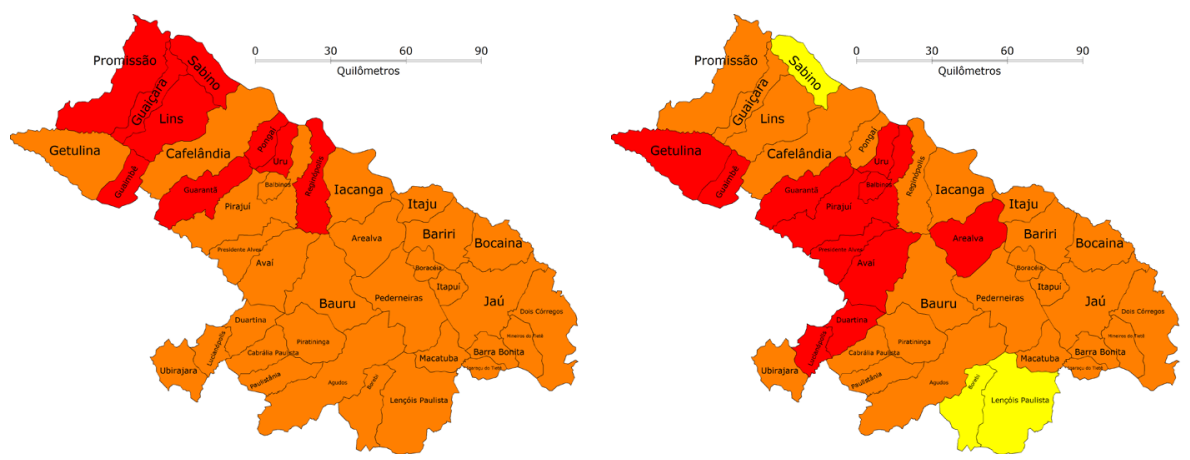

Figura 2 - Cálculo dos índices de Angstron e Monte Alegre para os municípios da REDEC-I7.

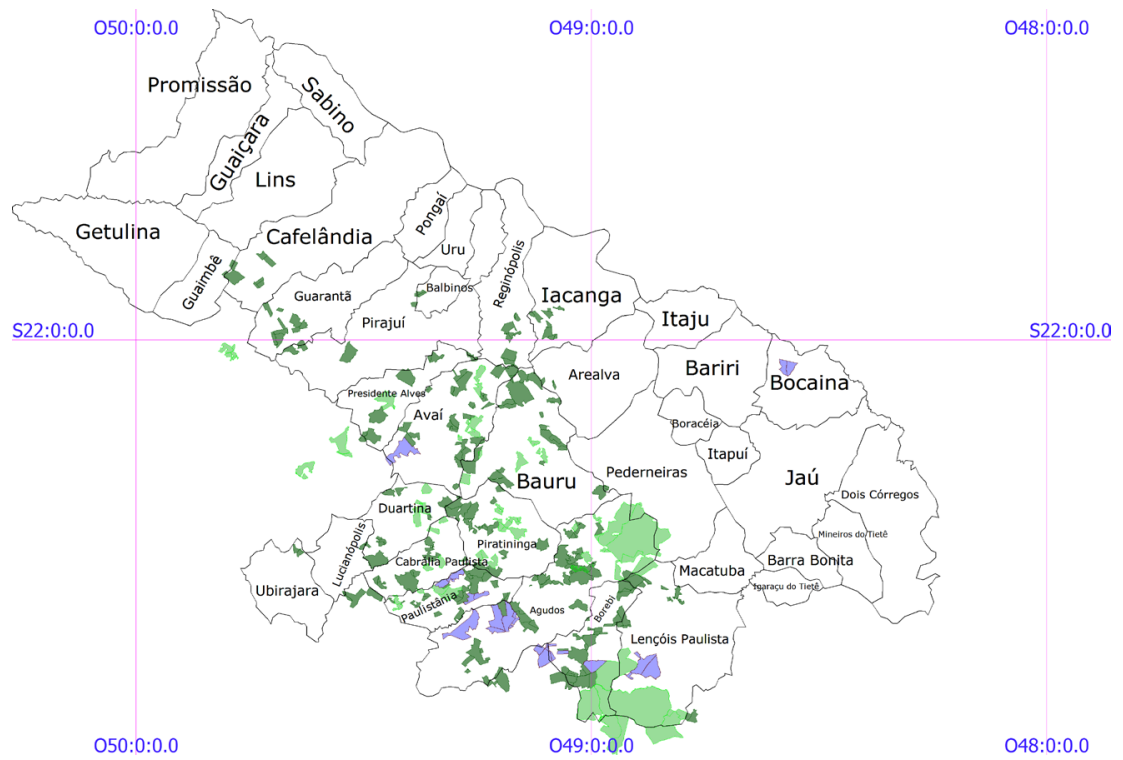

Figura 3 - Perímetros das empresas de refloretamento com alerta em função do índice de Angstrom previsto para o dia seguinte (12/09/2014).

\section{Conclusão}

A utilização de estudos para a avaliação do perigo de incêndio em tempo real constitui a melhor possibilidade de salvaguarda vidas, propriedades e recursos naturais. Além disso, a estimativa de índices de perigo de incêndio em curto prazo, com dados de observação e previsão numérica, tem em vista o apoio à tomada de decisões atualizadas.

Os índices calculados pelo sistema desenvolvido no CIADEN com a plataforma tecnológica TerraMA ${ }^{2}$, mostram que os alertas e os resultados obtidos podem ser utilizados como base de dados na elaboração de planos preventivos aos riscos de incêndios florestais. 
Esperamos que com o estabelecimento e acompanhamento de índices de perigo de incêndios florestais, por um período de tempo longo, em grandes áreas como a REDEC-17, permite estabelecer quais são as zonas potencialmente mais perigosas ou propícias à ocorrência de incêndios, permitindo assim a adoção de medidas preventivas e advertindo o grau de perigo.

\section{Bibliografia}

Lopes, E.S.S. TerraMA2 - Plataforma para monitoramento, análise e alerta a extremos ambientais. Apresentação de slides. Instituto Nacional de Pesquisas Espaciais (INPE). São José dos Campos-SP - 2012.

Castro, A.L.C. - Manual de desastres: desastres naturais. Brasília (DF): Ministério da Integração Nacional, 2003. 174 p. Disponível em: http://www.integracao.gov.br/c/document_library/get_ file?uuid=47a84296-d5c0-474d-a6ca-8201e6c253f4

Cavarsan, E.A. Utilização do geoprocessamento na prevenção e estratégias de combate a incêndios florestais no município de Cabrália Paulista - SP. Brasil, Programa de Pós-Graduação em Geografia/UEM,. 187 p. (Tese de Mestrado). 2008.

Soares, R. V. Índices de perigo de incêndio. Revista Floresta, v. 3, n. 3, p.19-40, 1972. 1972a.

Soares, R. V. Determinação de um índice de perigo de incêndio para a região centro paranaense, Brasil. Turrialba, Costa Rica, CATIE/IICA,. 72 p. (Tese de Mestrado). 1972b.

Soares, R. V. Prevenção e controle de incêndios florestais. ABEAS, 120 p. 1984. 